\title{
Fortaleciendo el vocabulario de la lengua extranjera inglés en infantes de tercer grado de primaria usando flashcards digitales
}

María Angélica García-Medina'

Corporación Universitaria del Caribe - CECAR maria.garciame@cecar.edu.co

ORCID: https://orcid.org/0000-0001-8454-9137

Luisa Margarita Severiche-Urda²

Corporación Universitaria del Caribe - CECAR

lui.110514@gmail.com

ORCID: https://orcid.org/0000-0002-6664-5667

Jennifer Eugenia Garay-Rodríguez ${ }^{3}$

Corporación Universitaria del Caribe - CECAR

jennifer.garay@cecar.edu.co

ORCID: https://orcid.org/0000-0003-2568-7120

Julio Luis Mendez-Vergara ${ }^{4}$

Corporación Universitaria del Caribe - CECAR

julio.mendez@cecar.edu.co

ORCID: https://orcid.org/0000-0002-1578-6451

DOI: https://doi.org/10.21158/2357514x.v7.n1.2019.2324

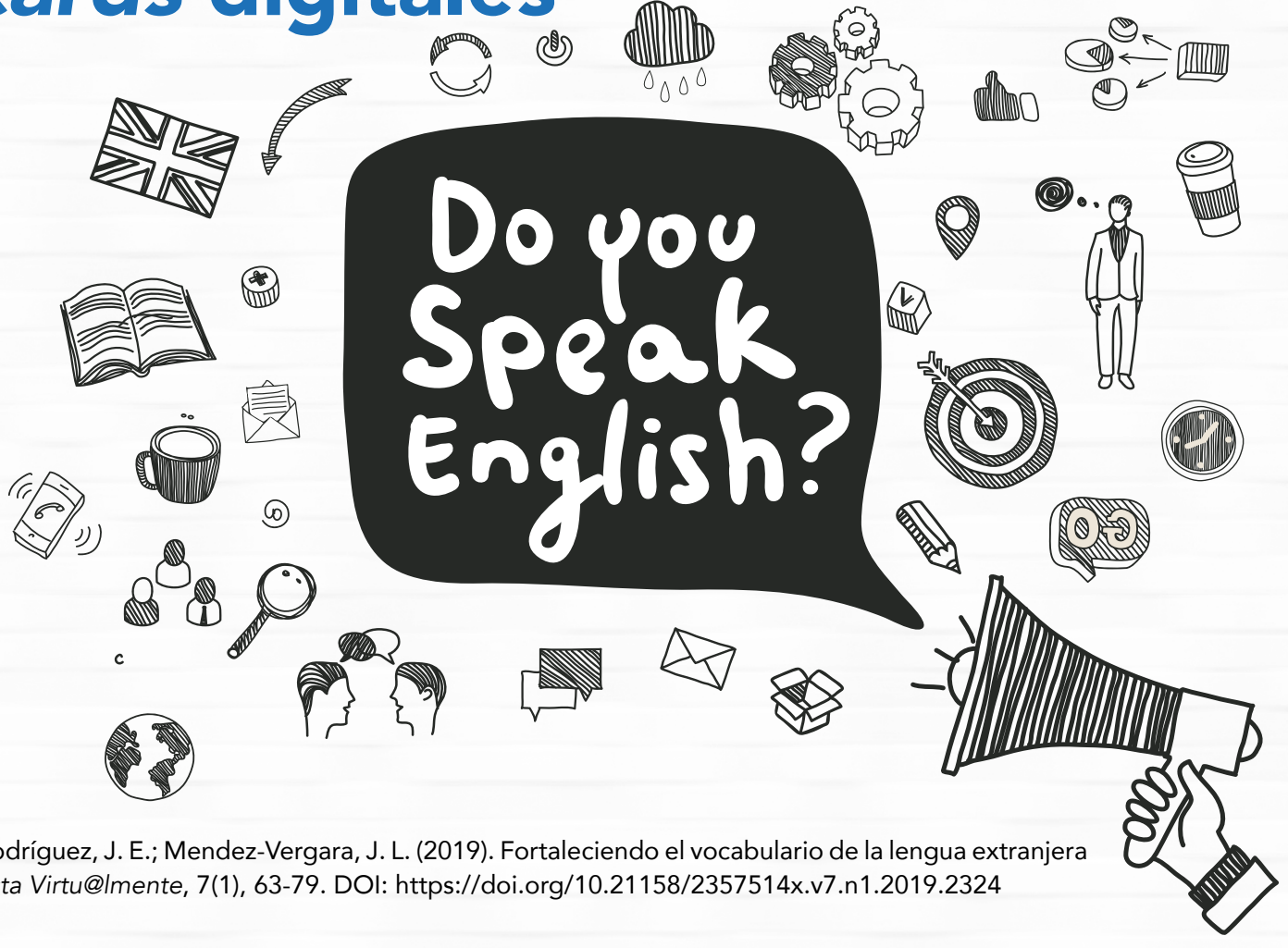

Cómo citar este artículo: García-Medina, M. A.; Severiche-Urda, L. M.; Garay-Rodríguez, J. E.; Mendez-Vergara, J. L. (2019). Fortaleciendo el vocabulario de la lengua extranjera inglés en infantes de tercer grado de primaria usando flashcards digitales Revista Virtu@lmente, 7(1), 63-79. DOI: https://doi.org/10.21158/2357514x.v7.n1.2019.2324

Fecha de recepción: 12 de enero de 2019

Fecha de aprobación: 04 de marzo de 2019

${ }^{1}$ Ingeniera de sistemas, egresada de la Fundación Universitaria San Martin, Especialista en docencia de la Corporación Universitaria del Caribe CECAR, Magister en Dirección e Ingeniería de Sitios Web, de la Universidad Internacional de La Rioja. Coordinadora Académica del programa de Ingeniería de Sistemas.

2 Licenciada en Educación Básica con Énfasis en Humanidades, Lengua Castellana e Inglés. Egresada de la Corporación Universitaria del Caribe CECAR.

${ }^{3}$ Licenciada en Educación Básica con Énfasis en Humanidades, Lengua Castellana e Inglés. Egresada de la Corporación Universitaria del Caribe CECAR.

${ }^{4}$ Licenciado en Educación Básica con Énfasis en Humanidades Ingles, de la Universidad de Córdoba. Docente del área de inglés de la Corporación Universitaria del Caribe CECAR. 


\section{RESUMEN}

Este proyecto tuvo como objetivo la implementación del uso de flashcards en formato digital para la enseñanza y el aprendizaje de un segundo idioma y a través de este artículo se reconstruye y describe esta experiencia.

En primera instancia se identificó el nivel de dominio que presentaban los estudiantes de tercer grado en el idioma inglés. Posteriormente se diseñaron estrategias que involucraron las flashcards en el desarrollo de cada una de las temáticas con el fin de fortalecer el vocabulario. El paradigma de investigación fue cuantitativo de corte descriptivo y como resultados se obtuvo el diseño de una estrategia pedagógica basada en el uso de las flashcards digitales.

De igual manera, se usó la herramienta PROPROFS, lo que permitió un aprendizaje activo en los estudiantes, promoviendo el desarrollo de la atención, la memoria y mayor concentración e incentivó las habilidades de retención y percepción a través de la participación activa en el aula de clases.

Como conclusión se tiene que la estrategia empleada a través del uso de flashcards digitales permite a los docentes una experiencia de enseñanza de la lengua extranjera de forma amena, puesto que en contextos rurales aprender un segundo idioma se vuelve una tarea ardua. Así mismo, las flashcards pueden ser utilizadas en compañía de los maestros, padres de familia y los mismos estudiantes y ayudan de manera significativa en el aprendizaje de un segundo idioma ya que fortalecen el vocabulario de los estudiantes.

Plabras clave: estrategia pedagógica; flashcards; enseñanza de lengua extranjera; enseñanza del inglés; herramientas educativas digitales; aprendizaje activo. 


\section{Strengthening the vocabulary of the foreign language -English- in third-grade infants by using digital flashcards}

\section{ABSTRACT}

This project aimed at implementating the use of flashcards in digital format for teaching and learning a second language, and by means of this article, this experience is reconstructed and described.

During the first instance, the level of proficiency of third grade students in the English language was identified. Subsequently, we designed strategies that involved flashcards in the development of each of the themes, in order to strengthen vocabulary. The research paradigm was quantitative descriptive and as a result the design of a pedagogical strategy based on the use of digital flashcards was obtained.

Similarly, the PROPROFS tool was used, allowing active learning in students, promoting the development of attention, memory, and greater concentration, and encouraging retention and perception skills by means of the active participation in the classroom.

As a conclusion, we may say that the strategy that was used through the use of digital flashcards allows teachers to experience foreign language teaching in an enjoyable way, since in the rural context, learning a second language becomes an arduous task. Likewise, flashcards can be used in the company of teachers, parents, and the students themselves, and help significantly in learning a second language as they strengthen the vocabulary of students.

Keywords: pedagogical strategy; flashcards; foreign language teaching; English teaching; digital educational tools; active learning. 


\section{Fortalecendo o vocabulário da língua estrangeira -inglês- em crianças da terceira série usando flashcards digitais}

\section{RESUMO}

Este projeto teve como objetivo a implementação do uso de flashcards em formato digital para ensinar e aprender um segundo idioma e, através deste artigo, essa experiência é reconstruída e descrita.

Primeiramente, foi identificado o nível de proficiência apresentado pelos alunos da terceira série no idioma inglês. Posteriormente, foram elaboradas estratégias que envolviam flashcards no desenvolvimento de cada um dos temas, a fim de fortalecer o vocabulário. O paradigma da pesquisa foi quantitativo descritivo e, como resultado, foi obtido o desenho de uma estratégia pedagógica baseada no uso de flashcards digitais.

Da mesma forma, foi utilizada a ferramenta PROPROFS, que permitiu aprendizado ativo nos alunos, promovendo o desenvolvimento da atenção, memória e maior concentração e incentivando as habilidades de retenção e percepção por meio da participação ativa na sala de aula.

Conclui-se que a estratégia utilizada pelo uso de flashcards digitais permite aos professores uma experiência do ensino de línguas estrangeiras de uma maneira agradável, uma vez que em contextos rurais a aprendizagem de um segundo idioma se torna uma tarefa árdua.

Da mesma forma, os flashcards podem ser usados na companhia de professores, pais e alunos e ajudam significativamente na aprendizagem de um segundo idioma, pois fortalecem o vocabulário dos alunos.

Palavras-chave: estratégia pedagógica; flashcards; ensino de línguas estrangeiras; ensino de inglês; ferramentas educacionais digitais; aprendizado ativo. 


\section{Renforcement du lexique en langue étrangère -anglais- au moyen de cartes flash numériques chez des enfants de troisième année de primaire}

\section{RÉSUMÉ}

Cet article décrit et reconstruit un projet visant à mettre en place l'utilisation de cartes flash mémoire au format numérique pour l'enseignement et l'apprentissage d'une seconde langue.

Il s'agit d'abord d'identifier le niveau des connaissances en anglais des élèves de troisième année de primaire pour ensuite élaborer des stratégies impliquant l'utilisation de cartes mémoire dans le développement de thématiques de renforcement lexical. Le paradigme de cette recherche repose sur une description quantitative dont le résultat a été la conception d'une stratégie pédagogique fondée sur I'utilisation de cartes flash numériques.

D'autre part, I'utilisation de l'outil PROPROFS a permis un apprentissage actif des étudiants, favorisant un travail de mémorisation, d'attention, de concentration, et encourageant les capacités de rétention et de perception grâce à une participation active durant la classe.

En conclusion, la stratégie d'utilisation de cartes mémoire numériques permet aux professeurs d'enseigner une langue étrangère plus efficacement en zones rurales, où cet enseignement est souvent difficile, dans la mesure où les cartes mémoire numériques peuvent être utilisées également en compagnie des parents et d'autres élèves des institutions éducatives favorisant ainsi l'apprentissage d'une seconde langue en renforçant le lexique des apprenants.

Mots-clés: stratégie pédagogique; cartes mémoire; enseignement des langues étrangères; enseignement de l'anglais; outils pédagogiques numériques; apprentissage actif. 


\section{Introducción}

Hoy día, el aprendizaje de una segunda lengua en las escuelas resulta importante, este es el caso de la lengua extranjera inglés, que se emplea cada vez más en las aulas de clases y en la vida social de los estudiantes, debido a que es el idioma más usado alrededor del mundo. Sin embargo, no se debe dejar de lado que cuando una persona aprende otra lengua, aprende algo más que el código lingüístico que le permite intercambiar información y conocimientos con los otros hablantes de esa lengua. Se apropia de "otra visión» del mundo y de la realidad que es representada a través de esa lengua (Martínez, 2009).

En el ámbito laboral, la lengua inglesa representa una cualificación extra que las universidades no pasan por alto y las nociones básicas del inglés se hacen cada vez más importantes en sus estudiantes. En este sentido, se necesita implementar estrategias de enseñanza y de aprendizaje de una segunda lengua para que desde las instituciones educativas se cree la cultura de generar espacios de interacción comunicativa en lengua inglesa, aunque no se tenga un contexto cultural para ello (Peñafiel, 2015).

De igual forma, la función del docente es relevante para adelantar planes y programas de mejoramiento que busquen dar respuesta a las debilidades encontradas en cada una de las evaluaciones de sus procesos en los ambientes de aula. Partiendo de esas debilidades, se hace necesario buscar estrategias acomodadas a los estilos de aprendizaje de los estudiantes, para que puedan tener un desempeño adecuado desde lo cognitivo, actitudinal y práctico en áreas de poca motivación como el inglés. Así mismo, en aras de la adquisición de niveles progresivos en este idioma, se hace necesario una innovación en el aula de forma permanente y ajustada a las realidades de los ambientes educativos que se puedan presentar.

Así mismo, se debe tener en cuenta que un propósito de las instituciones educativas es el fomento y desarrollo de las habilidades comunicativas básicas para leer, comprender, escribir, escuchar, hablar y expresarse correctamente en lengua castellana y una segunda lengua para tener un desempeño adecuado en cualquier contexto social de carácter nacional e internacional; es tarea de las instituciones educativas generar innovaciones y mediaciones pedagógicas para el desarrollo de estas competencias y saberes (Ministerio de Educación Nacional, 2006a).

En la Institución Educativa María Inmaculada (IEMI) del municipio de San Marcos, departamento de Sucre, más precisamente en el grado $3^{\circ} \mathrm{E}$ de la jornada vespertina, se llevó a cabo un proceso de observación directa, realización de las Pruebas Saber diagnósticas y análisis de los diferentes saberes evaluados en Pruebas Saber aplicadas por el Estado. De este modo, se pudo evidenciar una serie de falencias representadas en el bajo nivel de las competencias comunicativas en la lengua inglesa, que abarcan las competencias lingüísticas, pragmática y la sociolingüística. 
Por este motivo, se debe instar la promoción de espacios dinámicos que permitan la adquisición, desarrollo de habilidades sociolingüísticas y el dominio de lengua extranjera inglés de forma divertida, que integre los saberes que han sido impartidos por el docente y que serán reforzados con la puesta en práctica de actividades. Es entonces cuando el uso de flashcards digitales toma importancia, dado que es una estrategia que permite a los estudiantes visualizar, memorizar y aprender una segunda lengua de manera divertida y mucho más práctica.

\subsection{Marco conceptual}

En la búsqueda o creación de herramientas didácticas que ayuden a mejorar los aprendizajes de los estudiantes, se han propuesto diversas estrategias pedagógicas y la enseñanza de un segundo idioma no es la excepción. En esta investigación, se han tomado las flashcards digitales para incentivar no solo el aprendizaje de la nueva lengua si no de promover su estudio de forma amena y activa.

Las flashcards son tarjetas o imágenes que constan de dos partes; en un lado de la tarjeta se escribe la palabra que se quiere dar a conocer y en su revés aparece su traducción en el idioma inglés. Aunque tradicionalmente las flashcards se hacían de cartón, hoy en día contamos con flashcards online, que te permiten trasladar tu aprendizaje a cualquier lugar, sin la necesidad de cargar físicamente con ellas (Velásquez, 2014).
Así mismo, al hablar sobre su utilidad, se debe tener en cuenta que "Las flashcards son herramientas maravillosas para la enseñanza, ofrecen diversión y juegos interactivos de aprendizaje, para todos los niveles de educación, o para todos los sujetos o estudiantes» (Espeso, 2016).

En ese sentido, hacer uso de las flashcards digitales como estrategia metodológica en el proceso de enseñanza y aprendizaje del idioma extranjero inglés es importante, dado que permiten los estudiantes alcanzar competencias comunicativas a través del vocabulario obtenido.

En lo que corresponde a la realización de actividades interesantes y visualmente atractivas, las flashcards mantienen la mente activa, además, mejoran la retención y promueven las cuatro habilidades básicas: speaking, reading, writing y listening. Sin olvidar que se pueden adaptar y ajustar poco a poco para uso individual o grupal, según la necesidad.

En lo referente al lenguaje, Ríos (2010), basándose en la teoría de Noam Chomsky, expone que el lenguaje

es un conjunto finito o infinito de oraciones, cada una de ellas de longitud finita y construida a partir de un conjunto finito de elementos. Esta definición enfatiza las características estructurales del lenguaje sin adentrase en sus funciones y la capacidad de generar acción que tiene para un emisor y el receptor. Dicho aspecto es medular dentro de los estudios relacionados al lenguaje (p. 3). 
Por otro lado, la lengua materna en el ser humano es un proceso innato, es decir, es la primera que se aprende y, a medida que el niño y niña interactúan con su medio social, se les facilita el aprendizaje de una lengua extranjera, lo que les permite desenvolverse en distintos contextos. El lenguaje admite un conjunto de palabras formadas a partir de lo definido desde una perspectiva materna, la cual se acciona a través de decodificaciones por medio de la comunicación verbal y no verbal al momento de transmitir mensajes (escritos, orales o de imágenes). Por tal razón, las flashcards digitales se convierten en una herramienta fundamental para el aprendizaje de nuevas palabras y el refuerzo del vocabulario en cualquier idioma, en este caso, la lengua inglesa, para así fortalecer las competencias comunicativas por medio del uso de las TIC.

Las habilidades que aprenden o desarrollan los estudiantes con el empleo de las flashcards son múltiples, dado que desarrollan su capacidad mental, asocian vocabulario y participan interactivamente con conocimientos nuevos adquiridos con estas prácticas cada vez más familiares, de fácil uso, manejo y mucho más. Igualmente, los padres se benefician al tener este recurso o herramienta en sus manos, para ayudar a sus hijos en cualquier aprendizaje (González, 2013).

Es evidente que los estudiantes de cualquier nivel, sea de básica primaria, preescolar, niveles superiores, se encuentran inmersos dentro de lo más innovador que es la tecnología - los recursos audiovisuales; estas herramientas posibilitan el acercamiento de los estudiantes al aprendizaje de nuevos conocimientos, haciendo uso de estrategias como flashcards digitales, lo cual resulta divertido e interactivo para cualquier nivel.
Por su parte, Joao Rivas (Citado en González, 2013) en su obra Normas para construir flashcards plantea la aplicación de normas para confeccionar recursos didácticos, como son las flashcards, que atraen toda la atención de los estudiantes mediante la observación para transmitir ideas o mensajes definidos utilizando dibujos, colores con textos breves y comprensibles de una manera o forma más fácil y a través del uso de medios informáticos y tecnológicos que incluso ayudan a la conservación del medio ambiente al no hacer uso innecesario de papel, cartón, entre otros.

En este orden de ideas, los medios audiovisuales representan gran importancia para apoyar y llevar a cabo procesos de enseñanza, ya que posibilitan la adquisición de conocimientos de forma directa a través de herramientas innovadoras, tales como las flashcards digitales, que despiertan interés en los estudiantes y los acercan al uso adecuado del mundo de las nuevas tecnologías. Es un medio avanzado y variado que permite a los estudiantes aprender de forma más creativa, ir a su propio ritmo y ser constructores de su propio aprendizaje.

Las flashcards digitales son un recurso valioso para llevar a cabo procesos pedagógicos, puesto que facilitan la adquisición de nuevos aprendizajes y refuerzan de manera directa aprendizajes antes vistos. Finalmente, Johnson (2008), en su obra Aprender y enseñar lenguas extranjeras, expone que:

las flashcards son un recurso didáctico de uso común en las clases de inglés a niveles de educación básica y educación infantil, estas nos sirven para presentar un nuevo vocabulario y para repasar y afianzar el vocabulario ya estudiado, podemos utilizar al principio de la sesión, 
como primer contacto y punto de enlace con la sesión anterior y durante $\mathrm{o}$ al final de la misma para repasar el vocabulario visto con anterioridad (Citado por González, 2013, p. 23).

Lo anterior expone que el uso de las flashcards se ha convertido en un recurso didáctico innovador y ajustable en el proceso de enseñanza y aprendizaje, en la medida en que desarrolla habilidades de comprensión e interpretación del léxico en el idioma extranjero inglés, ya que, además de ser prácticas, estas presuponen una línea directa con el fortalecimiento de la memorización, explorando y reafirmando los conocimientos propuestos en el transcurso de los momentos pedagógicos.

Esta estrategia metodológica es una herramienta clave, práctica y básica que transforma de manera efectiva la enseñanza de nuevas palabras; además, contribuye a mejorar los conocimientos tanto teóricos, prácticos o simbólicos en los diferentes niveles de educación en el idioma extranjero.

Por otro lado, las flashcards permiten interactuar de manera directa con el estudiante por medio de imágenes, palabras y sonidos; así, se crean espacios diferentes por parte del docente y se producen reacciones favorables. Igualmente, se propone el trabajo en grupo y las relaciones significativas teórico/prácticas en los diferentes momentos de la clase. Esta herramienta clave se ha convertido en una ventaja a la hora de enseñar una segunda lengua, debido a su gran utilidad para fortalecer los aprendizajes construidos y reforzar el desarrollo de las competencias comunicativas.

\subsubsection{Aprendizaje de una segunda lengua.}

El Ministerio de Educación Nacional expone en la serie Lineamientos curriculares, idiomas extranjeros que:

El dominio u óptimo grado de competencia en idioma extranjero es un elemento de calidad de vida. En esta sociedad de culturas móviles y de acceso al conocimiento, los idiomas extranjeros se convierten en herramientas primordiales en la reconstrucción de las representaciones del mundo, en instrumentos básicos para la construcción de saberes, para llevar a cabo aprendizajes, para el manejo adecuado de las nuevas tecnologías y para el logro de una plena integración social y cultural (Ministerio de Educación Nacional, 2006a).

Para el aprendizaje de una segunda lengua se dan cuatro componentes básicos específicos: el fonológico, el morfológico, el semántico y el sintáctico. En lo planteado por Murado (2010):

Los individuos que tratan de adquirir un segundo idioma, se observa desde el punto de vista fonológico el niño infantil tiene una mayor capacidad para percibir sonidos que para producirlos correctamente, de la misma manera que un niño nativo. Además, tiende a simplificar la pronunciación de algunos sonidos, especialmente aquéllos que no existen en su propia lengua. Esto obliga al maestro hacer un previo diagnóstico para conocer los estilos y los ritmos de aprendizaje de sus estudiantes y de esta forma evitar errores de exclusión y generar ambientes de aula desde el área del inglés donde asuma una actitud y posición de lentitud y pausadamente y recolocaciones permanentes. 
En cuanto a la morfología, se debe aprender de la lengua inglesa marcadores de forma, como la progresiva -ing- $y$, con posterioridad, la -s- de los plurales y del genitivo. En cuanto al uso del pasado, las formas irregulares se adquieren antes que la regulares: mientras que un elemento tan significativo como el marcador de la tercera persona del singular del presente se olvida hasta etapas más avanzadas debido, básicamente, a este que elemento provoca en el niño escaso interés en lo que a comunicación se refiere (p.17).

En cuanto a la semántica, el infante que adquiere nuevo vocabulario en una lengua extranjera tiende a «sobregeneralizar», es decir, utiliza el mismo término para referirse a distintos conceptos, aunque en realidad es la falta de léxico la que provoca esto. El conjunto de palabras que se usa es simple y reducido y predominan los sustantivos de su contexto más cercano, los verbos de carácter general y los adjetivos relacionados con el tamaño y los colores (Murado, 2010).

En lo que a la sintaxis se refiere, el niño comienza dando sus primeros pasos, haciendo referencia al tiempo presente para, con el paso del tiempo y la práctica, construir estructuras sintácticas más desarrolladas y correctas en las que se refiere el pasado. La razón de esta evolución se comprende desde el momento en el que el niño se centra más en los aspectos discursivos y de comunicación de la lengua, que en los estrictamente gramaticales. El aprendizaje de frases negativas pasa por varias etapas, desde la colocación más básica de los componentes a la realización correcta de estas estructuras (Murado, 2010).
La adquisición de competencias en la lengua inglesa es un proceso pausado en el que se deben planificar adecuadamente las acciones pedagógicas que incluyan literalmente los cuatro componentes descritos. Es aquí donde el docente debe mostrar habilidades de innovación para hacer de este proceso una experiencia interactiva de explotación y descubrimiento de talentos, generando en sus estudiantes actitudes de participación y gusto por lo que hace, saberes donde relacione objetos del medio para la aprensión de los conceptos dados y habilidades para apropiarse de procedimientos prácticos sin ninguna dificultad.

\subsubsection{Flashcards digitales y su historia.}

Las flashcards digitales son tarjetas o imágenes que se utilizan como método de aprendizaje para desarrollar la memorización de cualquier conocimiento que se quiera impartir en las aulas de clase. Estas fichas se proyectan a través de medios audiovisuales, ya sea computadores, tabletas o proyectores, y el docente las crea con anterioridad mediante una herramienta o aplicación online. Cada ficha o tarjeta consta de dos partes: en un lado se escribe la palabra que se quiere dar a conocer y al revés de esta aparece su traducción en el idioma inglés.

Aunque, tradicionalmente, las flashcards estaban hechas de cartón, hoy en día contamos con aplicaciones web que permiten el diseño de flashcards digitales, que permiten trasladar el aprendizaje a cualquier lugar, sin la necesidad de cargar físicamente con ellas (Velásquez, 2013). El uso de estas fichas didácticas permiten al estudiante retener y memorizar de forma más completa los vocablos utilizados, afianzando 
el proceso de retención de palabras; al mismo tiempo, fortalecen sus competencias comunicativas, interactuando con la apropiación y uso de las nuevas tecnologías.

Otro de los beneficios de las flashcards digitales es que proporcionan una mayor flexibilidad, dado que permiten insertar imágenes, marcar las aprendidas, compartirlas fácilmente con amigos y descubrir flashcards de inglés listas para ser usadas (Velásquez, 2013). Por otro lado, el uso de las flashcards, desde siempre, ha tenido un valor en el campo educativo, ya que promueve la creatividad para enseñar y se presenta hoy en día como una estrategia novedosa, que cobra relevancia en los procesos de enseñanza y aprendizaje de vocabulario y fortalecimiento de las competencias comunicativas de los educandos. De este modo, se acerca a la comunidad educativa a las nuevas tecnologías y al manejo de la lengua extranjera inglés, ya que va de la mano con el uso de las nuevas tecnologías y permite la interacción con los medios audiovisuales.

Así mismo, las flashcards se consideran herramientas maravillosas para la enseñanza, ofrecen diversión y juegos interactivos de aprendizaje, para todos los niveles de la educación o para todos los sujetos o estudiantes (García, 2010), lo cual le permitirá al estudiante desenvolverse en futuros contextos.

\subsubsection{Flashcards y su uso educativo.}

Dentro del marco educativo, las flashcards han sido un recurso importante para construir conocimientos que contribuyen al desarrollo de habilidades comunicativas; motivan a los estudiantes en la construcción de sus propios conocimientos y, a la vez, los preparan con base en a las exigencias que la sociedad hoy día plantea. Es así como el aprendizaje y puesta en práctica de las nuevas tecnologías propenden el desarrollo en diferentes aspectos de la vida de los educandos en un futuro, como lo es la parte profesional, laboral y desarrollo personal. De este modo, facilita un desarrollo integral en su proyecto de vida; además, está en constante retroalimentación tecnológica e innova según las exigencias del contexto.

El gran impacto que ha tenido la tecnología en la educación con estos nuevos medios digitales presupone una responsabilidad por parte del docente y del educando. Se debe tomar el mundo digital como una estrategia de alto valor social y cultural, lo cual facilita la interacción y asimilación de experiencias positivas dentro y fuera del aula de clases, y por lo tanto evolucionar de forma positiva en la aplicación de nuevas metodologías en esta era digital, en función de formar personas integrales que estén a la vanguardia de las exigencias de la sociedad.

\subsection{Herramienta Proprofs - Knowledge Management Software}

La educación actualmente se ha convertido en un sistema digital en el que las TIC son los puntos de referencia para la adquisición de aprendizajes y conocimientos eficaces y significativos. Por ello, se toma como aspecto fundamental la atención, interactividad y refuerzo de saberes a través del uso de herramientas digitales que motiven al estudiante a generar el desarrollo de habilidades y competencias comunicativas. 
Por otro lado, Proprofs es una herramienta online que permite la creación de flashcards, test, juegos mentales y training maker, entre otros, a través de la interacción de elementos. Esta herramienta proporciona a los docentes una nueva visión acerca del proceso de enseñanza y las metodologías actuales que se llevan a cabo en las instituciones para alcanzar los logros esperados. De ahí que esta plataforma virtual se convierte en una ventaja para la adquisición de nuevos aprendizajes y facilita al maestro orientar de forma novedosa y llamativa los procesos pedagógicos. Cabe destacar que esta plataforma virtual crea fácilmente y comparte archivos de forma segura, además, centraliza el intercambio de conocimientos y fomenta el aprendizaje entre pares.

\section{Metodología}

La investigación está regida bajo los principios y fundamentos de paradigmas cuantitativos, que «utiliza la recolección de datos para probar hipótesis con base en la medición numérica y el análisis estadístico, con el fin establecer pautas de comportamiento y probar teorías» (Hernández, Fernández y Baptista, 2014). Así mismo, el tipo de estudio es descriptivo y tiene como objetivo describir el estado, las características, factores y procedimientos presentes en fenómenos y hechos que ocurren en forma natural, sin explicar las relaciones que se identifiquen (Lerma, 2009).

En cuanto a la población, estuvo constituida por los estudiantes del grado tercero de la Institución Educativa María Inmaculada de San Marcos, Sucre, Colombia. La muestra se- leccionada para la aplicación de la estrategia tuvo un carácter no probabilístico intencional, puesto que se escogió intencionalmente por el grupo investigador sin usar elementos aleatorios. Estuvo integrada por todos los estudiantes del grado $3^{\circ} \mathrm{E}$, que ascendían a un total de 24 , con edades oscilando entre los 8 y 13 años. Se caracterizaban por ser de estrato socioeconómico bajo; provenían de familias dedicadas a oficios artesanales y a la informalidad, como la pesca, la agricultura, oficios propios del agro y el mototaxismo. Para llevar a cabo la investigación, se dividió en las siguientes tres fases: a) fase 1: identificación del nivel del vocabulario en los estudiantes, b) fase 2: diseño de las flashcards en la herramienta Proprofs, y c) fase 3: valoración del uso de las flashcards digitales como estrategia pedagógica para fortalecimiento del vocabulario.

En cuanto a los instrumentos de recolección de datos, se utilizó la observación, que consiste en el registro sistemático, válido y confiable de comportamientos y situaciones observables (Hernández, Fernández y Baptista, 2014). Así, fue posible establecer la problemática y determinar las estrategias que utiliza el maestro titular para la enseñanza del inglés. Por otro lado, se utilizó el cuestionario, considerado como un conjunto de preguntas respecto a una o más variables que se van a medir (Hernández, Fernández y Baptista, 2014). Para el proyecto, el cuestionario se utilizó para determinar el nivel de vocabulario de los estudiantes de tercer grado. En él, se incluyeron preguntas asociadas a los criterios de reconocimiento de lugares, objetos, saludos y palabras del contexto en el idioma inglés. 
Es importante tener en cuenta que para la medición y resultados del test $A D I$ (actividad diagnóstica integral) se usaron tres niveles: a) nivel iniciado, donde se deben entender como nociones básicas que escalarmente sería reconocido como 1 , b) nivel logrado, se reconoce como 2, y c) nivel avanzado, como 3; es a este último nivel al que se esperaba llegar.

\section{Resultados}

\subsection{Nivel de vocabulario de los estudiantes de tercer grado}

En los estudiantes de tercer grado de la Institución Educativa María Inmaculada de San Marcos, Sucre, a través del test $A D I$ se identificó que los infantes muestran poco vocabulario para reconocer nombres de lugares y objetos. Se obtuvo que, de los 24 estudiantes, el $86 \%$ se encontraba en el nivel iniciado, el $11 \%$ se encontraban en el nivel logrado y solo el $3 \%$ de la muestra logró el nivel superado.

En cuanto a las palabras relacionadas al entorno, se observó que un $82 \%$ se encontraba en el nivel iniciado, el $11 \%$ alcanzaba el nivel logrado y un 7 \% de la muestra alcanzó el nivel superado en el logro evaluado para el reconocimiento de palabras relacionadas a temas del entorno. Así mismo, para la identificación de saludos, se observó que un $72 \%$ se encontraban en un nivel iniciado, el $14 \%$ alcanzaron el nivel logrado y tan solo un $14 \%$ lograban el nivel superado.
Estos resultados evidencian que los estudiantes tenían un alcance del vocabulario escaso o bajo para el nivel de formación en el que se encontraban, esto puede ser debido a las estrategias utilizadas por el maestro titular de la asignatura o al interés particular de cada estudiante.

\subsection{Estrategias diseñadas utilizando flashcards digitales}

El aprendizaje de la lengua extranjera inglés en los estudiantes de la educación básica primaria requiere de la aplicabilidad de estrategias pedagógicas dinámicas que les permitan desarrollar las competencias comunicativas necesarias en el área.

Este proyecto describe principalmente el uso de las flashcards digitales, dado que estas son un soporte visual que facilita la comprensión oral de los alumnos, así como el aprendizaje de nuevo vocabulario (Usán, 2013). Se empleó esta estrategia motivacional e innovadora para fortalecer las competencias comunicativas de la lengua extranjera inglés al permitir una interacción directa de los estudiantes con la herramienta virtual Proprofs.

Las actividades que se propusieron estaban enmarcadas desde la parte de conocimientos previos, actividades lúdicas, producción desde la escucha, la observación y pronunciación, a través de la implementación de las flashcards digitales. Las actividades desarrolladas son las siguientes: 


\subsubsection{The animals.}

Mediante la presentación de las flashcards digitales a través de diversos dispositivos móviles, los estudiantes interactuaron con ellas al escuchar y pronunciar los nombres de los diversos animales en el idioma inglés.

Figura 1. Actividad «The animals», diseñada en Proprofs

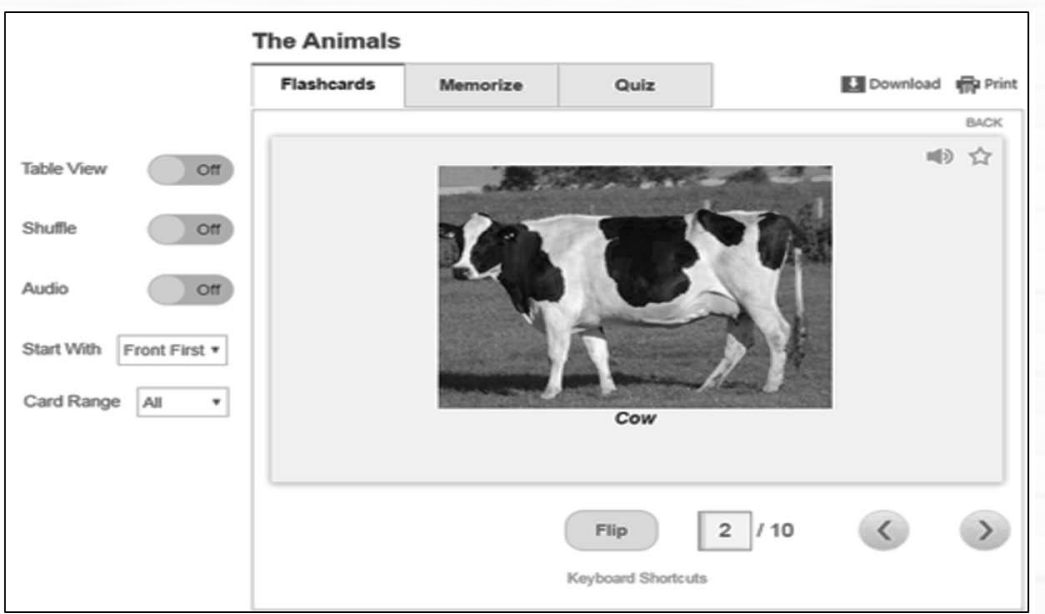

Fuente. Elaboración propia.

\subsubsection{The professions and occupations.}

Esta actividad consistió en que cada uno de los estudiantes imite una profesión u ocupación. Una vez realizado el juego de roles, a cada estudiante se les entregó la tableta. En ellas se trabajaron las diferentes ocupaciones a través de la estrategia flashcards digitales con la herramienta Proprofs, en la cual los estudiantes escucharon, pronunciaron y escribieron cada una de las palabras registradas en la tarjeta interactiva.
Figura 2. The professions and occupations, diseñada en Proprofs

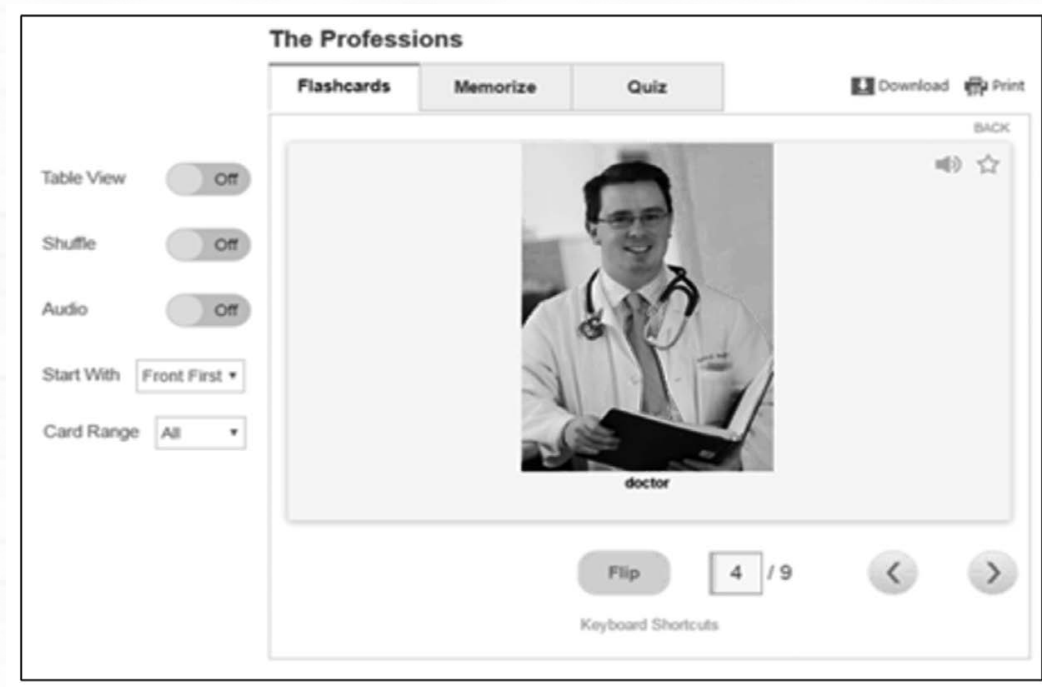

Fuente. Elaboración propia.

\subsubsection{The clothes}

La actividad consistió en aprender los diferentes tipos de prendas que se deben utilizar en cada una de las estaciones del año, para ello, los estudiantes recibieron dispositivos móviles, con los que interactuaron mediante las tarjetas interactivas, escuchando y pronunciando cada una de las palabras. 
Figura 2. The clothes, diseñada en Proprofs

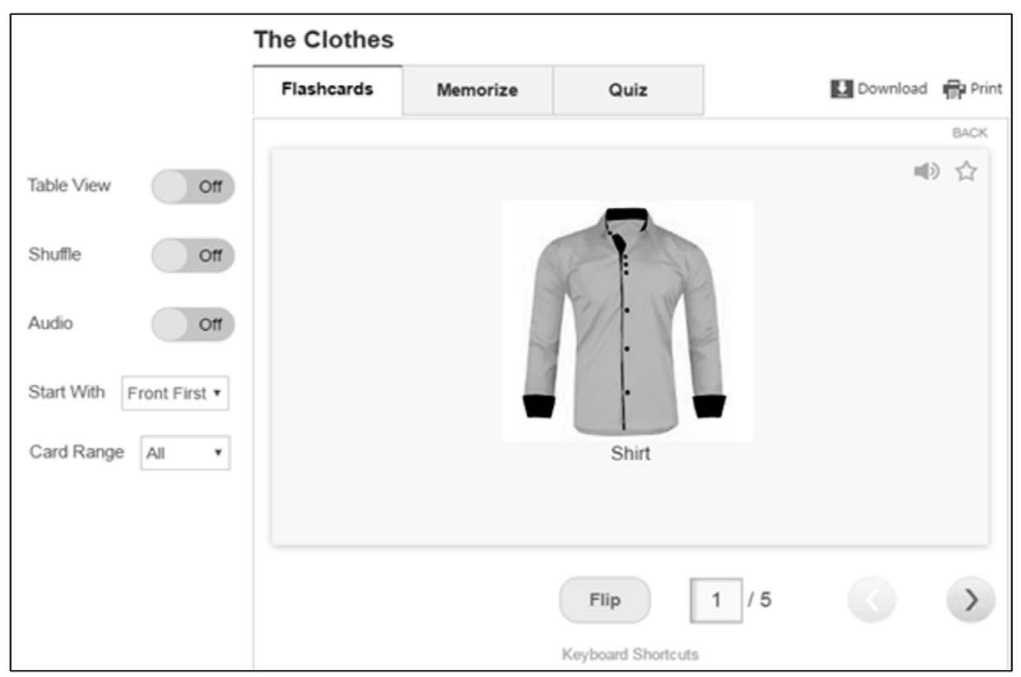

Fuente. Elaboración propia.

A través del uso de la estrategia flashcards, se evidencia que los niveles de vocabulario aumentaron en los estudiantes, ya que la repetición y la asociación de objetos también indica que aprender es operar con ideas o con objetos, tal como la teoría de Piaget (1970) lo describe, en la cual el aprendizaje se da cuando el esquema de asimilación sufre acomodación mediado por el equilibrio mayorante (Rodríguez y Larios, 2006).

Respecto a la operación, uno de los principales autores de la teoría del conductismo operante, Edward Lee Thorndike (1913) citado por Schunk (2012), establece un conexionismo neuronal y el refuerzo generador de aprendizaje a través de cinco leyes principales y cinco subsidiarias o subordinadas. Una de las leyes subordinadas es el cambio asociativo, que indica que es posible cambiar una respuesta de un estímulo a otro. Si una respuesta puede mantenerse intacta a través de una serie de cambios en la situación estimuladora.

De este modo, en la enseñanza de la lengua inglesa se hace necesario evocar palabras que asocien el contexto del individuo, por ejemplo: la palabra vaca evoca a un animal del campo o que pertenece a una finca, lo que la convierte en una característica determinante; la palabra cow en lengua inglés, evoca el mismo animal del campo o de una finca. Entonces las palabras (estímulos) vaca y cow originan la misma respuesta (Rodríguez y Larios, 2006).

Cabe destacar, igualmente, que una vez implementadas las diversas estrategias, se observó una mejora considerable en el vocabulario de los estudiantes en los diferentes aspectos valorados. En cuando al reconocimiento de lugares y objetos, se observó que del $86 \%$ de estudiantes que estaban en iniciado, un $50 \%$ de ellos pasaron a un nivel logrado. Para el reconocimiento del entorno en el idioma inglés, el $60 \%$ pasaron al nivel logrado; por ello, se destaca que emplear elementos del contexto del estudiante hace determinante el uso de asociaciones.

En cuanto a los saludos en el idioma inglés se observó una apropiación del vocabulario de forma aceptable, predomina en este caso que, del $100 \%$ de la muestra, un $70 \%$ se encontró en el nivel superado, lo que indica que los estudiantes son capaces de reconocer los saludos y dar respuestas a estos y viceversa. 
Para finalizar, se señala que, emplear un método de enseñanza como las flashcards digitales implica que los estudiantes realicen asociaciones a través del reconocimiento de la palabra escrita y su significado, como lo señalan Miles y Ehri (2017), la lectura de palabras a primera vista no se limita a palabras deletreadas de forma extraña o palabras de uso frecuente. Por el contrario, el objetivo de la lectura eficiente es hacer que todas las palabras reconozcan palabras para que se activen automáticamente en la memoria.

\section{Conclusión}

La estrategia empleada de las flashcards digitales permite a los docentes enseñar la lengua extranjera inglés de forma amena, puesto que en contextos rurales aprender un segundo idioma se vuelve una tarea ardua. Así mismo, las flashcards digitales pueden ser utilizadas en compañía de los maestros, padres de familia y/o los mismos estudiantes y ayudan de manera significativa en el aprendizaje de un segundo idioma, ya que fortalecen el vocabulario de los estudiantes.

Durante este proyecto, según las puntuaciones obtenidas desde el test ADI, se establece que el aprendizaje con flashcards promueve en los estudiantes el desarrollo de la atención, la memoria y mayor concentración, incentivado las habilidades de retención y percepción a través de la participación activa en el aula de clases.
En ese sentido, hay una convergencia con lo expuesto por el Marco Común Europeo de Referencia, donde se afirma que los recursos visuales tienen importancia destacada en la enseñanza y se indica que hacer uso de ellas enriquece la experiencia sensorial; son base del aprendizaje, facilitan la adquisición y fijación del aprendizaje. Así mismo, enmarcan que este tipo de aprendizaje tiene un fuerte poder motivador y dado que estimula la imaginación y la capacidad de abstracción del alumno, constituye una de las fuentes de motivación más importantes. Lo anterior lleva a economizar el tiempo, ya que las largas explicaciones son ventajosamente sustituidas por la simple observación de un ejemplar real o de un modelo, estimulan las actividades de los alumnos y enriquecen el vocabulario de los alumnos (Consejo de Europa, 2001).

Así mismo, con la implementación de las tecnologías de la información y comunicación (TIC) en las aulas de clases, esta herramienta se puede generalizar, sus buenos resultados pueden promover nuevos proyectos digitales y, desde la aplicación de la estrategia, las flashcards digitales pueden fortalecer los procesos de enseñanza y aprendizaje. 


\section{Referencias}

Murado, J. L. (2010). Didáctica de inglés en educación infantil. Métodos para la enseñanza y el aprendizaje de la lenguan inglesa. Bogotá: Ediciones de la U.

Espeso, P. (11 de abril de 2016). Anki, una interesante herramienta para crear gratis tus flashcards digitales. Recuperado de http://bit.ly/2mt89Cd

González, E. (2013). Las flash cards en el desarrollo del léxico del inglés en los estudiantes del décimo año de educación básica del Colegio Nacional Andrés Bello de la cuidad de Quito, año lectivo 2012 - 2013. (Tesis de licenciatura). Universidad Central del Ecuador. Quito, Ecuador. Recuperado de http:// bit.ly/2ksgW6F

Hernández, R.; Fernández, C.; Baptista, M. (2014). Metodología de la investigación (7 ed.). México D.F.: McGraw-Hill.

Lerma, H. (2009). Metodología de la investigación: propuesta, anteproyecto y proyecto (4 ed.). Bogotá: Ecoe ediciones Ltda.

Consejo de Europa. (2001). Marco común europeo de referencia para las lenguas: aprendizaje, enseñanza, evaluación. Madrid: Anaya.

Martínez, N. (2009). Por qué los estudiantes de las escuelas públicas no aprenden inglés. Dià-logos, Revista semestral del Instituto de Investigaciòn y formaciòn pedagògica de la Universidad Don Bosco. Recuperado de http://bit.ly/2m1qOEK

Ministerio de Educación Nacional. (2006a). Serie lineamientos curriculares, Idiomas Extranjeros. Recuperado de http://bit. ly/2kq21d2
Ministerio de Educación Nacional. (2006b). Estándares Básicos de Competencias en Lenguas Extranjeras: Inglés. Recuperado de http://bit.ly/2kv5A1N

Peñafiel, I. D. (2015). Las flashcards como estrategia didáctica en el proceso de aprendizaje de vocabulario. (Trabajo de grado). Corporación Universitaria del Caribe (CECAR). Sincelejo, Colombia. Recuperado de http://bit.ly/2/ZsQp2

Miles, K.; Ehri, L. (2017). Learning to Read Words on Flashcards: Effects of Sentence Contexts and Word Class in Native and Nonnative English-Speaking Kindergartners. Early Childhood Research Quarterly, 41(4), 103-113. DOI: https://doi. org/10.1016/j.ecresq.2017.06.001

Ríos, I. (2010). El lenguaje: herramienta de reconstrucción del pensamiento. Revista Razón y Palabra (72). Recuperado de http://bit.ly/2kvd440

Rodríguez, E.; Larios, B. (2006). Teorías cognitivas recientes. En Teorías del aprendizaje. Del conductismo radical a la teoría de los campos conceptuales. Bogotá: Actualización Pedagógica Magisterio.

Schunk, D.H. (2012). Teorías del aprendizaje. Una perspectiva educativa. (6a ed.) México: Pearson.

Usán, S. (2013). Instrumentos de hoy, instrumentos de ayer, la enseñanza cultural en el aula de inglés. (Tesis de maestría). Universidad Internacional de la Rioja. Zaragoza, España. Recuperado de http://bit.ly/2kKZvOW

Velásquez, M. (2013). Cómo Aprender Idiomas Usando Flashcards. Recuperado de http://bit.ly/2kVETDA 